\title{
Hypothermic machine perfusion ameliorates inflammation during ischemia-reperfusion injury via sirtuin-1-mediated deacetylation of nuclear factor- $\kappa B$ p65 in rat livers donated after circulatory death
}

\author{
CHENG ZENG ${ }^{1-4}$, XIAOYAN HU ${ }^{1-4}$, WEIYANG HE ${ }^{1-4}$, YANFENG WANG ${ }^{1-4}$, \\ LING LI $^{1-4}$, YAN XIONG ${ }^{1-4}$ and QIFA YE ${ }^{1-5}$ \\ ${ }^{1}$ Zhongnan Hospital of Wuhan University; ${ }^{2}$ Institute of Hepatobiliary Diseases of Wuhan University; ${ }^{3}$ Transplant \\ Center of Wuhan University; ${ }^{4}$ Hubei Key Laboratory of Medical Technology on Transplantation, Wuhan University, \\ Wuhan, Hubei 430071; ${ }^{5}$ The Third Xiangya Hospital of Central South University, Research Center of National Health \\ Ministry on Transplantation Medicine Engineering and Technology, Changsha, Hunan 410013, P.R. China
}

Received July 26, 2016; Accepted July 13, 2017

DOI: $10.3892 / \mathrm{mmr} .2017 .7738$

\begin{abstract}
Hypothermic machine perfusion (HMP) effectively reduces ischemia-reperfusion injury (IRI) in livers donated after circulatory death (DCD) when compared with cold storage (CS). However, the underlying mechanisms remain unclear. The current study aimed to investigate the cellular mechanisms by which HMP ameliorates the inflammatory response during IRI. Adult male Sprague-Dawley rat livers were exposed to $30 \mathrm{~min}$ of warm ischemia following cardiac arrest and preserved by CS or HMP for $3 \mathrm{~h}$ ( $\mathrm{n}=3$ per group). The severity of IRI was assessed in vitro on normothermic reperfusion for $2 \mathrm{~h}$, and intrahepatic resistance (IHR) and bile production were subsequently recorded. The perfusate was analyzed for transaminase leakage and oxygen consumption. Livers were subsequently subjected to histological examination, and measurement of adenosine triphosphate (ATP) levels, malondialdehyde (MDA) content, superoxide dismutase (SOD) activity, nicotinamide adenine dinucleotide (NAD) ${ }^{+}$levels and the ratio of $\mathrm{NAD}^{+} / \mathrm{NADH}$. In addition, the protein expression of sirtuin-1 (SIRT-1), acetylated-nuclear factor $-\kappa \mathrm{B}(\mathrm{NF}-\kappa \mathrm{B})$ p65 and NF- $\mathrm{B}$ p 65 was detected by western blotting, and the mRNA expression of the inflammatory cytokines interleukin (IL)- 6 and tumor necrosis factor (TNF)- $\alpha$ was determined by reverse transcription-quantitative polymerase chain reaction. Compared with CS, HMP resulted in significantly lower IHR,
\end{abstract}

Correspondence to: Professor Qifa Ye, Institute of Hepatobiliary Diseases of Wuhan University, Wuhan University, 169 Donghu Road, Wuhan, Hubei 430071, P.R. China

E-mail: yqf_china@163.com

Key words: hypothermic machine perfusion, cold storage, donated after circulatory death liver, acetylation, sirtuin-1, nuclear factor- $\kappa \mathrm{B}$, ischemia-reperfusion transaminase leakage and MDA levels, and higher oxygen consumption, ATP levels and SOD activity. In addition, improved preservation of hepatic histology was observed in HMP compared with CS. The mRNA expression of $\mathrm{NF}-\kappa \mathrm{B}$ p65, IL-6 and TNF- $\alpha$ was significantly decreased in the HMP group compared with CS samples. Under HMP preservation, SIRT-1 activity and protein expression were increased, while the protein expression of acetylated-NF- $\kappa \mathrm{B}$ p 65 was decreased, compared with CS. These results indicate that HMP may reduce the inflammatory response during IRI via SIRT-1-mediated deacetylation of NF- $\kappa \mathrm{B}$ p65. These findings may provide a theoretical basis for the clinical application of HMP as an effective strategy to preserve DCD livers.

\section{Introduction}

Liver transplantation is considered to be the most effective solution to various end-stage liver pathologies. The persistent shortage of suitable donors that have had brain death confirmed has prompted a reexamination of donors after circulatory death (DCD) to extend the pool of organs for transplantation. However, DCD is considered as a primary risk factor to inferior liver transplantation outcomes and complications, including primary non-function and early allograft dysfunction, due to the higher vulnerability to ischemia-reperfusion injury (IRI) (1). Therefore, novel strategies that improve the preservation conditions of DCD organs and retain their vitality are required $(2,3)$. Various experimental and clinical reports have indicated the effectiveness of hypothermic machine perfusion (HMP) in improving DCD liver preservation when compared with cold storage (CS), as HMP attenuates IRI compared with CS (4-6). HMP is a dynamic hypothermic technique for preserving transplantation organs. It simulates the physiological conditions of organs by supplying them with oxygen and/or key nutrients, and removing waste products $(4,7)$. However, the molecular mechanisms underlying the attenuation of IRI by HMP remain unclear. 
Post-translational modification has important functions in various cellular processes (8). Acetylation, one type of post-translational modification, is essential for the activation of the transcription factor nuclear factor- $\kappa \mathrm{B}(\mathrm{NF}-\kappa \mathrm{B})(9-11)$, which is one of the critical contributors to IRI (12-15). Acetylation of RelA/p65 at lysine 310, a subunit of NF- $\mathrm{NB}$, was reported to modulate various transcriptional activities of $\mathrm{NF}-\kappa \mathrm{B}$ (11). Activated NF- $\kappa \mathrm{B}$ is controlled by a feedback mechanism via deacetylation. Sirtuin-1 (SIRT-1), a member of the sirtuin family, is a deacetylase that has been reported to reduce IRI in a nicotinamide adenine dinucleotide (NAD) ${ }^{+}$-dependent manner (16-18). Furthermore, SIRT-1 has been demonstrated to inhibit NF- $\kappa$ B by deacetylating RelA/p65 at lysine 310 in non-small-cell lung cancer cells (19). Therefore, given the protective role of SIRT-1 in IRI, the present study aimed to investigate the modulatory effects of HMP on SIRT-1 in regulating $\mathrm{NF}-\kappa \mathrm{B}$ p65 activity, which in turn protects DCD livers from IRI.

\section{Materials and methods}

Animals. A total of 6 adult male Sprague-Dawley rats (age, 8-10 weeks; weight, 250-300 g) were obtained from the Experimental Animal Culture Center of Hubei Centers for Disease Control (Wuhan, China). All animals were housed under standard laboratory conditions (temperature, $25 \pm 2{ }^{\circ} \mathrm{C}$; relative humidity, $55 \pm 5 \%$; a 12 -h light/dark cycle) with free access to food and water. All animal procedures were approved by the Animal Ethics Committee of Wuhan University and handled in accordance with the Experimental Animal Regulations of the People's Republic of China and the Guide for the Care and Use of Laboratory Animals of the USA (20).

HMP and isolated perfused rat liver (IPRL) system. A photograph of the recirculating perfusion system is presented in Fig. 1. It consisted of a thermostat water bath (Jiaxing Zhongxin Medical Instruments Co., Ltd., Jiaxing, China) containing water or ice water mixture, a liver container for perfusion installed in the water bath, a temperature sensor (Jiangsu Singhe Electronic Technology Co., Ltd., Suqian, China) inserted into the container to measure the fluid temperature, a peristaltic pump (Shanghai Jingke Industrial Co., Ltd., Shanghai, China), a hollow-fiber membrane oxygenator (Dongguan Kewei Medical Instrument Co., Ltd., Dongguan, China), a self-made bubble trap used to communicate between the ' $F$ ' shunt tube and the oxygenator to deliver the bubble, a flow meter (Nanjing Careermen Instrument Co., Ltd., Nanjing, China) connected to one side of the ' $F$ ' shunt tube to measure the hepatic inflow, and the other side of the ' $F$ ' shunt tube was used as a probe for liver inflow sample collection. To measure the perfusion portal pressure, a portal vein cannula was connected to the baroreceptor of a BL-420F biological functional system (Chengdu Techman Software Co., Ltd., Chengdu, China).

The HMP system (Fig. 1A and B) consisted of the above-mentioned recirculating perfusion system without an oxygen supply. The water bath was powered off and filled with ice water mixture to maintain the temperature of perfusate at $0-4^{\circ} \mathrm{C}$.
The IPRL system (Fig. 1A and C) consisted of all of the above-mentioned parts of the recirculating perfusion system. In the present study, the top of the water in the water bath, where a container for the rat liver was installed, had a lower temperature compared with the bottom. According to the results of a preliminary experiment, the water bath was set at $40^{\circ} \mathrm{C}$ to maintain the temperature of perfusate in the liver container at $36-37^{\circ} \mathrm{C}$. Krebs-Henseleit buffer (Macgene Biotechnology, Ltd., Beijing, China) with $4 \%$ dextran was added into the liver container for reperfusion (21). The perfusate was oxygenated $\left(95 \% \mathrm{O}_{2}\right.$ and $5 \% \mathrm{CO}_{2} ; \mathrm{pO}_{2}>500 \mathrm{~mm} \mathrm{Hg}$ ) and recirculated for $2 \mathrm{~h}$ at $36-37^{\circ} \mathrm{C}$ under a portal venous perfusion pressure of $10.3 \mathrm{~mm} \mathrm{Hg}$, as described previously (22).

Surgery and experimental design. Rats were anesthetized with chloral hydrate $(10 \% ; 3 \mathrm{ml} / \mathrm{kg}$; Sinopharm Chemical Reagent Co., Ltd., Shanghai, China) by intraperitoneal injection. A midline incision was used to expose the abdomen, the liver was freed from all ligamentous attachments and the common bile duct was cannulated with an epidural guiding tube (Jiangsu Changfeng Medical Industry Co., Ltd., Yangzhou, China) to collect the total bile outflow during reperfusion.

Cardiac death was induced by hypoxia following incision of the diaphragm without portal clamping or prior heparinization (23). The warm ischemia time in situ began from the point of cardiac arrest. After $30 \mathrm{~min}$, an intravenous injection of $2 \mathrm{ml}$ saline containing $100 \mathrm{IU}$ heparin (Nanjing Jiancheng Bioengineering Institute, Nanjing, China) via the right iliac vein was performed (24). Subsequently, the hepatic artery was ligated, the portal vein was cannulated by a self-made polyethylene (PE) catheter (outer diameter, $2.1 \mathrm{~mm}$; inner diameter, $1.8 \mathrm{~mm}$ ) and flushed in situ with $20 \mathrm{ml} 4^{\circ} \mathrm{C}$ histidine-tryptophan-ketoglutarate (HTK) solution (Dr. Franz Köhler Chemie GmbH, Bensheim, Germany). The liver was then removed and a PE catheter (internal diameter, $3 \mathrm{~mm}$ ) was cannulated into the suprahepatic inferior vena cava for the collection of hepatic effluent (25). Finally, the liver was randomly assigned either to the CS or HMP group.

In the CS group $(n=3)$, livers underwent static CS in $150 \mathrm{ml}$ HTK solution at $0-4^{\circ} \mathrm{C}$ for $3 \mathrm{~h}$. In the HMP group $(n=3)$, livers were connected to the HMP system (Fig. 1B). HMP was performed via the portal vein with $0-4^{\circ} \mathrm{C}$ HTK solution $(150 \mathrm{ml})$ for $3 \mathrm{~h}$ at a rate of $0.5 \mathrm{ml} / \mathrm{g} / \mathrm{min}$ without oxygenation, as detailed previously (25).

Investigating IRI using an IPRL system. IPRL is an in vitro system that permits the investigation of physiological and pathophysiological conditions in rat livers, including IRI in DCD livers after transplantation (26). After $3 \mathrm{~h}$ of CS or HMP preservation, the viability of all livers was evaluated using IPRL, as detailed previously (23). To simulate the slow rewarming period in liver transplantation, livers were left untouched on a petri dish at room temperature for $\sim 15 \mathrm{~min}$ prior to reperfusion (23). During the normothermic reperfusion (NR), which was performed for $2 \mathrm{~h}$, the portal pressure and portal flow were measured for the calculation of the intrahepatic resistance (IHR) using the following formula: IHR $(\mathrm{mmHg} / \mathrm{ml} / \mathrm{min})=$ portal pressure $(\mathrm{mmHg}) /$ portal flow $(\mathrm{ml} / \mathrm{min})$.

Hepatic effluent was collected through the PE catheter cannulated in the suprahepatic vena cava every hour and 
analyzed for the enzyme activities of alanine transaminase (ALT), aspartate transaminase (AST) and lactate dehydrogenase $(\mathrm{LDH})$, and oxygen $\left(\mathrm{O}_{2}\right)$ consumption rate. The enzyme activities were assessed using ALT (cat. no. C009-2), AST (cat. no. C010-2) and LDH assay kits (cat. no. A020-2; all Nanjing Jiancheng Bioengineering Institute), according to the manufacturer's protocol.

Hepatic $\mathrm{O}_{2}$ consumption was used to assess the metabolic activity of the livers. Perfusate samples were respectively collected from the portal inflow and the PE catheter placed in the suprahepatic vena cava. Subsequently, the $\mathrm{O}_{2}$ content in perfusate samples was measured immediately by a $\mathrm{pH}$-blood gas analyzer (i-STAT; Abbott Point of Care, Inc., Princeton, NJ, USA). $\mathrm{O}_{2}$ consumption by livers was calculated according to standard formulas, as detailed previously (22).

Bile was collected through the epidural guiding tube placed in the common bile duct every hour. As the density of bile was equal to the water, the bile flow was gravimetrically estimated and expressed as $\mu \mathrm{l} / \mathrm{h} / \mathrm{g}$ liver.

At the end of the $2 \mathrm{~h}$ in vitro isolated perfusion period (the end of the IPRL assay), livers were weighed and a portion was fixed in $10 \%$ formaldehyde for $24 \mathrm{~h}$ at room temperature for histological analysis. The rest of the liver was immersed in liquid nitrogen and stored at $-80^{\circ} \mathrm{C}$ until subsequent experiments.

Measurement of adenosine triphosphate (ATP) content in livers. Liver samples $(20 \mathrm{mg})$ stored at $-80^{\circ} \mathrm{C}$ were homogenized using $4.2 \%$ perchloric acid and $1 \mathrm{mM}$ diethylenetriamine pentaacetic acid. Subsequently, samples were centrifuged at $14,000 \times \mathrm{g}$ and $4^{\circ} \mathrm{C}$ for $5-10 \mathrm{~min}$, and the supernatants were collected and brought to $\mathrm{pH} 6$ by $69 \% \mathrm{~K}_{2} \mathrm{CO}_{3}$. Finally, ATP content was measured using an ATP assay kit (Nanjing Jiancheng Bioengineering Institute), according to the manufacturer's protocol. Protein concentration was determined using the bicinchoninic acid (BCA) method; ATP levels were expressed as $\mu \mathrm{mol} / \mathrm{g}$ protein.

Measurement of malondialdehyde (MDA) content and superoxide dismutase (SOD) activity in livers. Frozen liver samples were prepared and centrifuged as described for determination of ATP levels, subsequently, the supernatants were collected and used immediately for MDA content and SOD activity assays, according to the standard protocol of the MDA assay (cat. no. A003-1; Nanjing Jiancheng Bioengineering Institute) and SOD assay kits (cat. no. A001-1-1; Nanjing Jiancheng Bioengineering Institute).

Histology. The formaldehyde (10\%)-fixed liver samples were paraffin-embedded and serially cut to $5-\mu \mathrm{m}$ sections, which was followed by staining with hematoxylin and eosin (HE; hematoxylin staining for 5-15 $\mathrm{min}$ and eosin staining for 1-3 min; all performed at room temperature) for histological analysis at x200 magnification using a light microscope.

Western blotting. Rat liver tissues were homogenized and lysed with lysis buffer $(50 \mathrm{mM}$ Tris- $\mathrm{HCl}, 137 \mathrm{mM} \mathrm{NaCl}$, $10 \%$ glycerol, $100 \mathrm{mM}$ sodium orthovanadate, $1 \mathrm{mM}$ PMSF, $10 \mathrm{mg} / \mathrm{ml}$ aprotinin, $10 \mathrm{mg} / \mathrm{ml}$ leupeptin, $1 \%$ Nonidet P-40 and $5 \mathrm{mM}$ protease inhibitor cocktail; $\mathrm{pH}$ 7.4; Beyotime
Institute of Biotechnology, Jiangsu, China). Protein concentration was determined by a BCA assay (Beyotime Institute of Biotechnology). The proteins (30 $\mu \mathrm{g} /$ lane) were combined with $\beta$-mercaptoethanol and bromophenol blue for electrophoresis, and separated via 10\% PAGE. Proteins were then transferred to polyvinylidene difluoride membranes (Bio-Rad Laboratories, Inc., Hercules, CA, USA), which were blocked with $5 \%$ skim milk for $2 \mathrm{~h}$ at room temperature. Membranes were then incubated overnight at $4{ }^{\circ} \mathrm{C}$ with the following primary antibodies: Rabbit anti-SIRT-1 (cat. no. bs-0921R; 1:400; Beijing Biosynthesis Biotechnology Co., Ltd, Beijing, China), rabbit anti-NF-кB p65 (cat. no. bs-20355R; 1:400; Beijing Biosynthesis Biotechnology Co., Ltd.), rabbit anti-acetyl (K310) p65 (cat. no. ab19870; 1:300; Abcam, Cambridge, UK) and rabbit anti- $\beta$-actin (cat. no. GB13001-3; 1:1,500; Wuhan Goodbio Technology Co. Ltd., Wuhan, China). This was followed by incubation with horseradish peroxidase-conjugated goat anti-rabbit IgG (cat. no. GB23303; 1:5,000; Wuhan Goodbio Technology Co. Ltd.) for $1 \mathrm{~h}$ at room temperature. The reactive bands were visualized using an Electrochemiluminescence kit (cat. no. P0018; Beyotime Institute of Biotechnology). Quantification of protein bands was performed using ImageJ v1.42q software (National Institutes of Health, Bethesda, MA, USA).

Reverse transcription-quantitative polymerase chain reaction (RT-qPCR) for interleukin (IL)-6 and tumor necrosis factor (TNF)- $\alpha$ mRNAs in liver tissues. RNA was extracted from the frozen liver tissue of rats using TRIzol reagent (Thermo Fisher Scientific, Inc., Waltham, MA, USA), according to the manufacturer's protocol, and quantified using a NanoDrop instrument (Thermo Fisher Scientific, Inc.). RNA was reverse-transcribed into cDNA using the Thermo Scientific RevertAidä First Strand cDNA Synthesis kit (Thermo Fisher Scientific, Inc.) with a total volume of $20 \mu \mathrm{l}$, containing total RNA $(1 \mu \mathrm{g})$, Oligo(dT) $)_{18}$ primer $(1 \mu \mathrm{l}), 5 \mathrm{X}$ Reaction Buffer (4 $\mu \mathrm{l})$, RiboLock RNase Inhibitor $(20 \mathrm{U} / \mu \mathrm{l} ; 1 \mu \mathrm{l}), 10 \mathrm{mM}$ dNTP Mix ( $2 \mu \mathrm{l})$, RevertAid M-MuLV RT (200 U/ $\mu \mathrm{l} ; 1 \mu \mathrm{l})$ and water (nuclease-free). The reverse transcription reactions were performed with the following conditions: $42^{\circ} \mathrm{C}$ for $1 \mathrm{~h}$ and $75^{\circ} \mathrm{C}$ for 5 min. qPCR was performed using the $\mathrm{SYBR}^{\circledR}$ Select Master Mix (Applied Biosystems; Thermo Fisher Scientific, Inc.) in a StepOnePlus Real-Time PCR System (Applied Biosystems; Thermo Fisher Scientific, Inc.). The thermocycling conditions were as follows: $50^{\circ} \mathrm{C}$ for $2 \mathrm{~min}, 95^{\circ} \mathrm{C}$ for $10 \mathrm{~min}$, followed by 40 cycles of $95^{\circ} \mathrm{C}$ for $10 \mathrm{sec}$ and $60^{\circ} \mathrm{C}$ for $30 \mathrm{sec}$. All of the reactions were performed 3 times in triplicate. The relative mRNA expression was analyzed by the comparative threshold cycle $\left(2^{-\Delta \Delta \mathrm{Cq}}\right)$ method (27) and the results were normalized to those of $\beta$-actin. The primer sequences used were as follows: TNF- $\alpha, 5$ '-AGTCCGGGCAGGTCTACTTT-3' (forward) and 5'-TTCAGCGTCTCGTGTGTTTC-3' (reverse); IL-6, 5'-GGT CTTCTGGAGTTCCGTTTC-3' (forward) and 5'-TCCATT AGGAGAGCATTGGAA-3' (reverse). $\beta$-actin, 5'-TGCTAT GTTGCCCTAGACTTCG-3' (forward) and 5'-GTTGGCATA GAGGTCTTTACGG-3' (reverse).

Assessment of $\mathrm{NAD}^{+} / \mathrm{NADH}$ in the liver. The levels of $\mathrm{NAD}^{+}$ and NADH in liver tissue homogenate were measured using the Coenzyme I NAD $(\mathrm{H})$ content test kit (Nanjing Jiancheng 


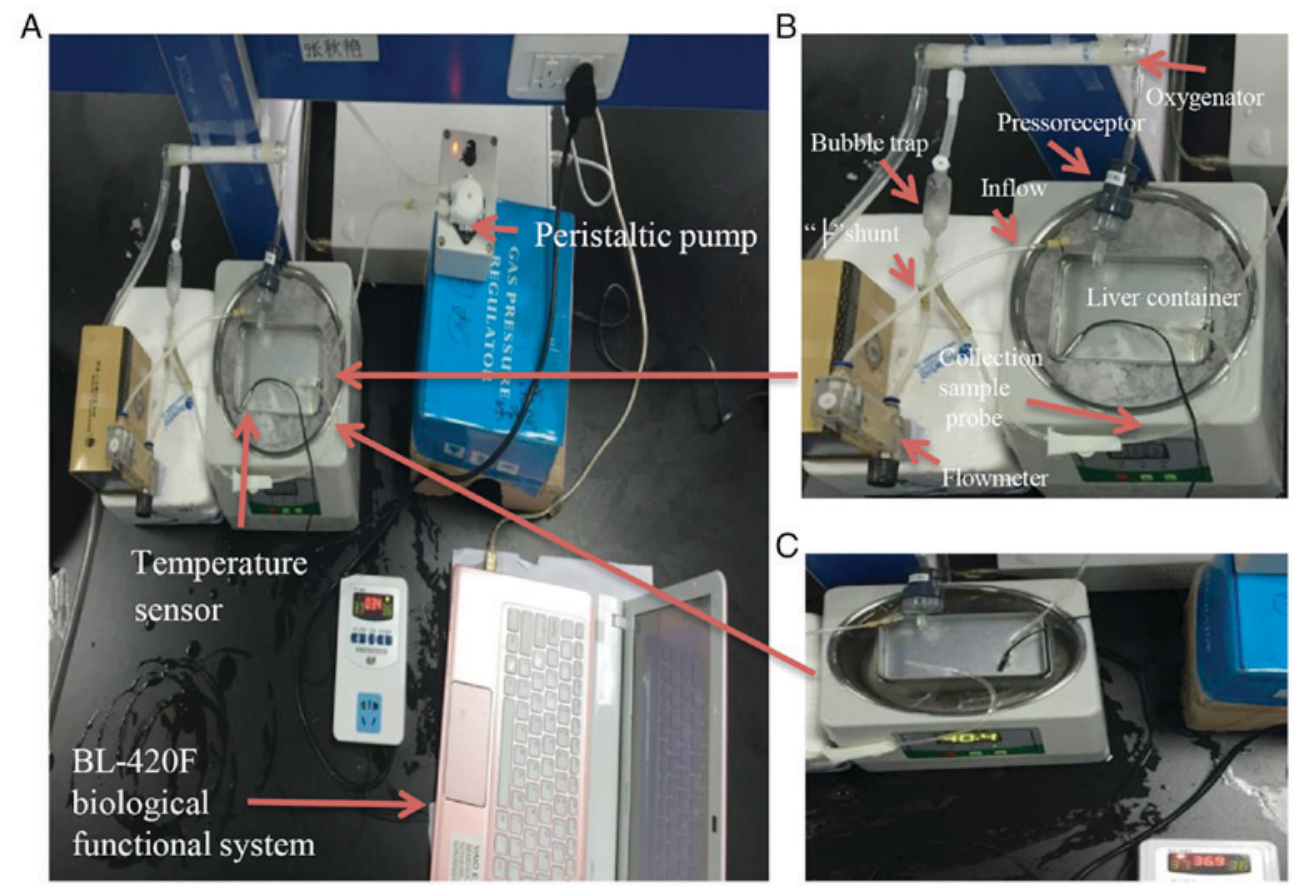

Figure 1. Photographs of the system used for HMP and isolated perfusion of rat livers. (A) Recirculating perfusion system. (B) HMP system. (C) Isolated perfused rat liver system. HMP, hypothermic machine perfusion.

Bioengineering Institute). Total $\mathrm{NAD}^{+}$and NADH were quantified according to the manufacturer's protocol.

Statistical analysis. Statistical analysis was performed using SPSS v16.0 software (SPSS, Inc., Chicago, IL, USA). Data are presented as the mean \pm standard error of the mean. After the assumption of normality and equal variance between groups was confirmed, the differences between CS and HMP groups were analyzed using independent samples t-tests. $\mathrm{P}<0.05$ was considered to indicate a statistically significant difference.

\section{Results}

$H M P$ decreases IHR during NR. The portal pressure and portal flow were used to calculate the IHR of DCD livers preserved by static CS or HMP at various time points during NR. A significant difference was observed between the CS and HMP groups at each analyzed time point during NR (Fig. 2A). IHR in the livers in the CS group was significantly higher compared with the HMP group at $0(9.36 \pm 1.08$ vs. $5.20 \pm 0.78 \mathrm{mmHg} / \mathrm{ml} / \mathrm{min} ; \mathrm{P}=0.036), 60$ (4.43 \pm 0.57 vs $0.63 \pm 0.19 \mathrm{mmHg} / \mathrm{ml} / \mathrm{min} ; \mathrm{P}=0.003)$ and $120 \mathrm{~min}(2.67 \pm 0.67$ vs. $0.56 \pm 0.13 \mathrm{mmHg} / \mathrm{ml} / \mathrm{min} ; \mathrm{P}=0.037)$.

$H M P$ reduces the release of $A L T, A S T$ and $L D H$ during $N R$. To characterize the hepatocyte viability, the release of ALT, AST and LDH enzymes was determined during reperfusion. Increasing levels of ALT, AST and LDH enzymes were observed during the course of NR in CS and HMP groups. However, a significant reduction of ALT enzyme leakage was observed in the HMP group compared with the CS group at $0(24.67 \pm 5.61$ vs. $66.33 \pm 8.67 \mathrm{U} / 1 ; \mathrm{P}=0.016), 60(56.00 \pm 13.58$ vs. $176.67 \pm 19.68 \mathrm{U} / \mathrm{l} ; \mathrm{P}=0.007)$ and $120 \mathrm{~min}(208.67 \pm 20.28 \mathrm{vs}$. 435.00 $\pm 63.89 \mathrm{U} / \mathrm{l} ; \mathrm{P}=0.028$ ), as presented in Fig. 2B. Similar patterns were observed for AST and LDH levels in the HMP and CS groups. AST levels were significantly reduced in the HMP group at $0(29.33 \pm 7.54$ vs. $98.00 \pm 13.58 \mathrm{U} / 1 ; \mathrm{P}=0.011)$, $60(75.33 \pm 17.42$ vs. $167.33 \pm 16.95 \mathrm{U} / 1 ; \mathrm{P}=0.019)$ and $120 \mathrm{~min}$ (218.33 \pm 25.99 vs. $448.67 \pm 47.91 \mathrm{U} / 1 ; \mathrm{P}=0.013$; Fig. 2C). Similarly, LDH levels were significantly decreased in the HMP group compared with the CS group at $0(469.77 \pm 92.05$ vs. $1,301.97 \pm 193.53 \mathrm{U} / 1 ; \mathrm{P}=0.018), 60(1,096.50 \pm 115.13$ vs. $2,058.33 \pm 199.25 \mathrm{U} / \mathrm{l} ; \mathrm{P}=0.014)$ and $120 \mathrm{~min}(2,588.50 \pm 237.96$ vs. 3,784.07 $\pm 172.23 \mathrm{U} / \mathrm{l} ; \mathrm{P}=0.015$; Fig. 2D).

HMP improves $\mathrm{O}_{2}$ consumption rate, ATP levels and bile production in DCD rat livers. Efficient $\mathrm{O}_{2}$ consumption is crucial for ATP production, which maintains the energy status of cells. The influence of CS and HMP on the $\mathrm{O}_{2}$ consumption of DCD rat livers was analyzed during reperfusion (Fig. 3). DCD livers in the HMP group exhibited significantly higher rates of $\mathrm{O}_{2}$ consumption when compared with the CS group at $0\left(1.50 \pm 0.21\right.$ vs. $0.59 \pm 0.10 \mu \mathrm{mol} \mathrm{O}_{2} / \mathrm{min} / \mathrm{g}$ liver; $\left.\mathrm{P}=0.017\right)$, $60(1.71 \pm 0.16$ vs. $0.73 \pm 0.06 \mu \mathrm{mol} \mathrm{O} / \mathrm{min} / \mathrm{g}$ liver; $\mathrm{P}=0.005)$ and $120 \mathrm{~min}\left(1.74 \pm 0.14\right.$ vs. $0.73 \pm 0.07 \mu \mathrm{mol} \mathrm{O}_{2} / \mathrm{min} / \mathrm{g}$ liver; $\mathrm{P}=0.003)$. Anaerobic metabolism leads to rapid depletion of ATP, which in turn leads to the disruption of homeostasis. Therefore, the present study also determined ATP levels in HMP or CS preserved DCD livers. In the HMP group, ATP levels in liver tissues obtained after $2 \mathrm{~h}$ reperfusion were significantly higher compared with the CS group (21.80 \pm 2.01 vs. $4.16 \pm 0.93 \mu \mathrm{mol} / \mathrm{g}$ protein; $\mathrm{P}=0.001$; Fig. $4 \mathrm{~A}$ ). However, no significant difference in the production of bile flow was observed between livers preserved by HMP or CS (Fig. 4B). Notably, the bile flow production was marginally higher in the HMP group compared with the CS group, however, this did not reach statistical significance after $120 \mathrm{~min}$ reperfusion $(9.29 \pm 2.48$ vs. $7.90 \pm 2.36 \mu \mathrm{l} / \mathrm{h} / \mathrm{g}$ liver; $\mathrm{P}=0.704)$. 

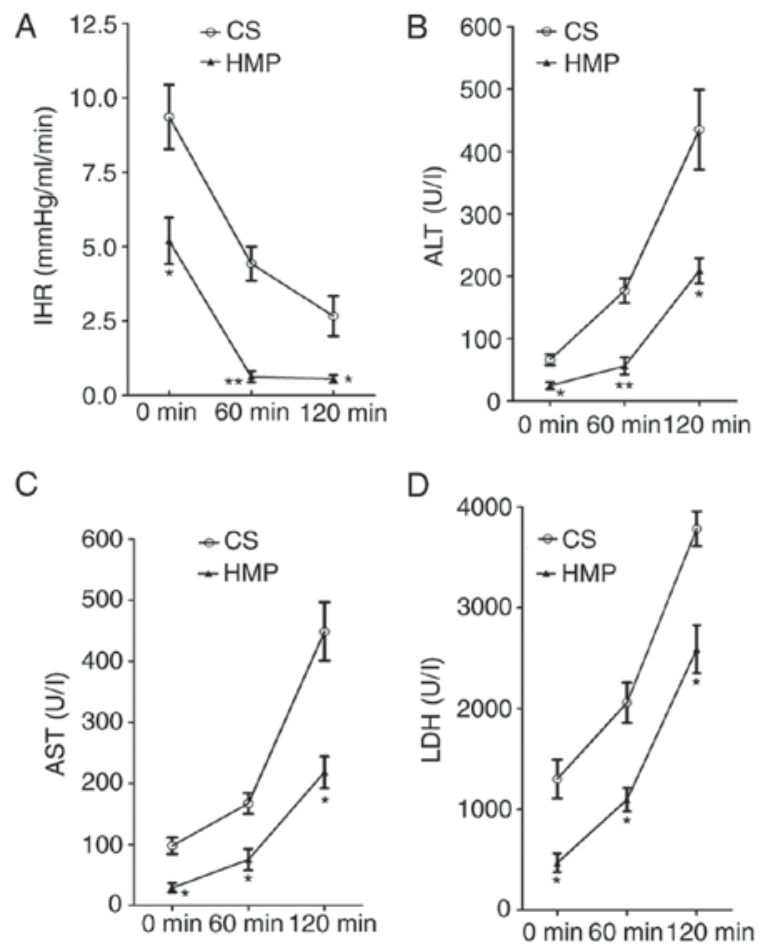

Figure 2. Measurement of IR and ALT, AST and LDH activities during reperfusion. (A) IR during reperfusion. Release of (B) ALT, (C) AST and (D) LDH during reperfusion. Data are presented as the mean \pm standard error of the mean. ${ }^{*} \mathrm{P}<0.05$ and ${ }^{* *} \mathrm{P}<0.01$ vs. CS. IR, intrahepatic resistance; ALT, alanine transaminase; AST, aspartate transaminase; LDH, lactate dehydrogenase; CS, cold storage; HMP, hypothermic machine perfusion.

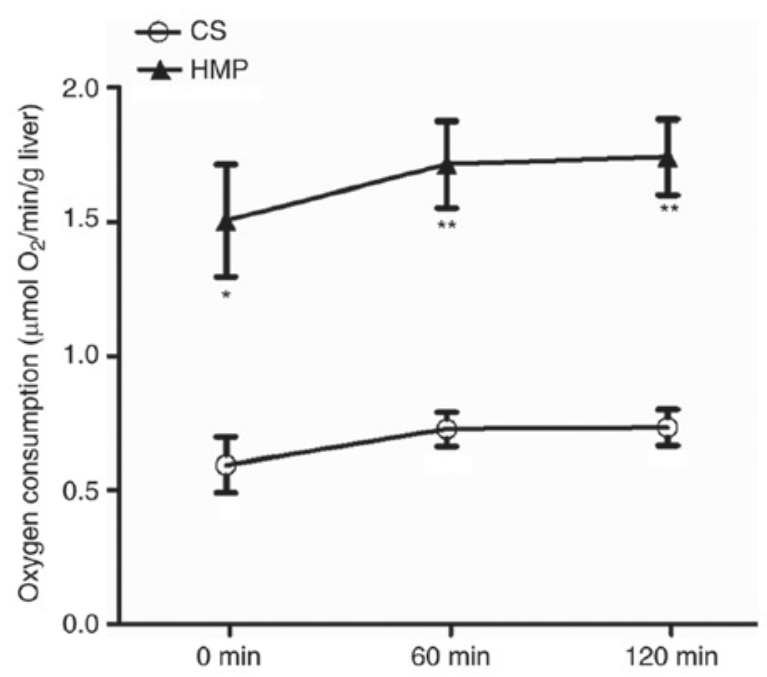

Figure 3. Oxygen consumption during reperfusion in CS and HMP groups. Data are presented as the mean \pm standard error of the mean. ${ }^{*} \mathrm{P}<0.05$ and ${ }^{* *} \mathrm{P}<0.01$ vs. CS. CS, cold storage; HMP, hypothermic machine perfusion.

HMP attenuates oxidative damage following NR. MDA, an end-product of lipid oxidation, serves as an important indicator for the assessment of oxidative damage. There was a significant reduction in MDA levels in livers preserved by HMP compared with those preserved by CS $(2.57 \pm 0.45$ vs. $10.52 \pm 1.86 \mathrm{nmol} / \mathrm{mg}$ protein; $\mathrm{P}=0.014 ;$ Fig. $5 \mathrm{~A}$ ), which indicates lower levels of oxidative stress following HMP. In addition, an increase in the activity of SOD was observed in livers of the
A
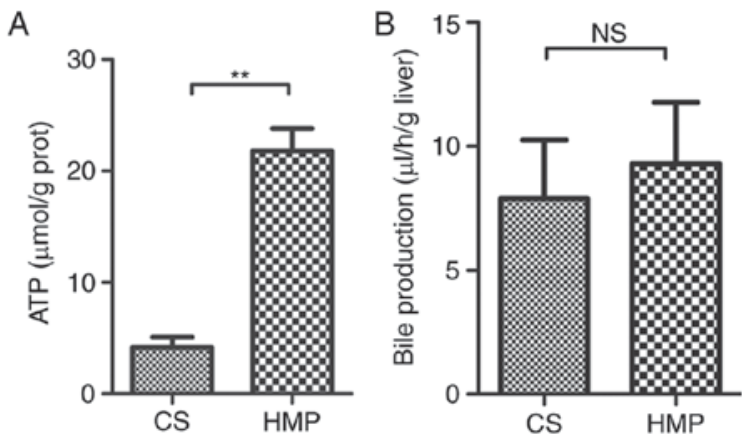

Figure 4. ATP levels and bile production in CS and HMP groups. Tissue levels of (A) ATP and (B) hepatic bile production ratio at the end of reperfusion in CS and HMP groups. Data are presented as the mean \pm standard error of the mean. ${ }^{* *} \mathrm{P}<0.01$, as indicated. ATP, adenosine triphosphate; CS, cold storage; HMP, hypothermic machine perfusion; prot, protein.
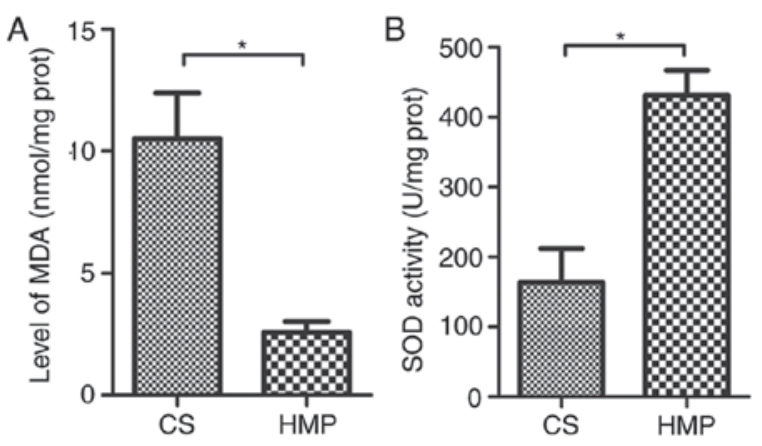

Figure 5. Levels of oxidative markers at the end of reperfusion in CS and HMP groups. Tissue levels of (A) MDA and (B) SOD in CS and HMP groups. Data are presented as the mean \pm standard error of the mean. ${ }^{*} \mathrm{P}<0.05$, as indicated. CS, cold storage; HMP, hypothermic machine perfusion; MDA, malondialdehyde; SOD, superoxide dismutase; prot, protein.

HMP group compared with the CS group (431.41 \pm 35.99 vs. $163.34 \pm 48.97 \mathrm{U} / \mathrm{mg}$ protein; $\mathrm{P}=0.012$; Fig. $5 \mathrm{~B}$ ), indicating a higher antioxidant activity in the cells preserved by HMP.

HMP improves the hepatic morphology of DCD rats. HE staining demonstrated a more intact hepatic cytoarchitecture in tissues preserved by HMP compared with those preserved by CS. In the HMP group, hepatic sinusoids were dilated due to the perfusion pressure, however, few sinusoidal endothelial cells exhibited signs of shrinkage and detachment. In addition, areas of hydropic changes and necrosis were limited in livers preserved by HMP compared with those preserved by CS (Fig. 6).

$H M P$ attenuates hepatic $N F-\kappa B$ p65-induced inflammatory response in DCD rats via SIRT-1-mediated deacetylation of the acetylated $-N F-\kappa B p 65$. The present study subsequently determined the protein expression of $N F-\kappa B$ p 65 and observed a significant decrease in the expression in livers preserved by HMP compared with the CS group $(0.41 \pm 0.06$ vs. $1.05 \pm 0.09 ; \mathrm{P}=0.004$; Fig. 7). The activation of $\mathrm{NF}-\kappa \mathrm{B}$ p65 is reversed by deacetylation. Therefore, to investigate whether HMP attenuated hepatic $N F-\kappa B$ p 65 activity via SIRT-1-mediated deacetylation of $\mathrm{NF}-\kappa \mathrm{B}$ p 65 , the protein expression of SIRT-1 and acetylated-NF- $\mathrm{B}$ p65 (an active 


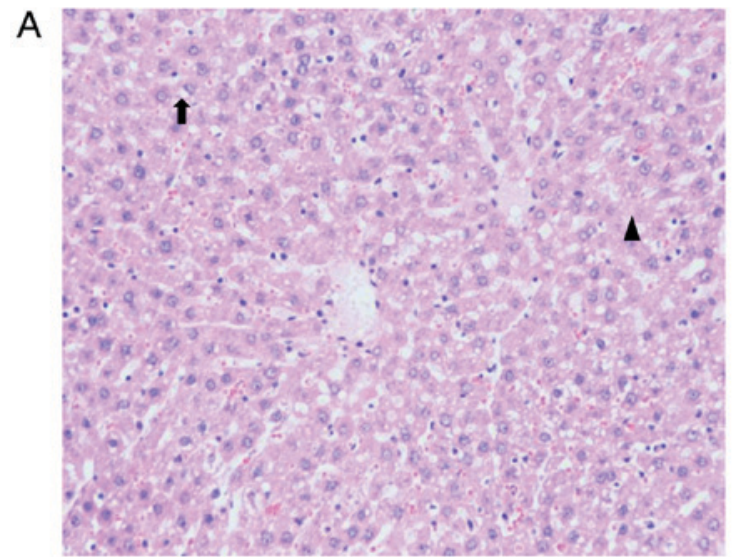

B

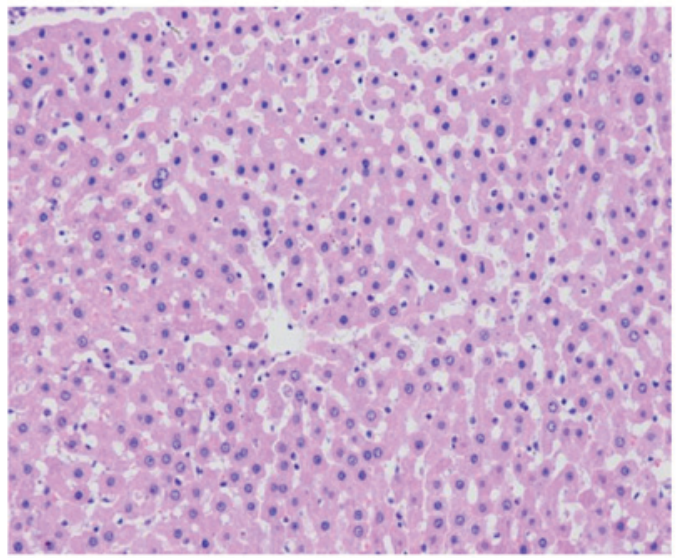

Figure 6. Hematoxylin and eosin staining of tissues at the end of reperfusion in (A) cold storage and (B) hypothermic machine perfusion groups Magnification, x200. The arrow indicates an area with hydropic changes and the arrow head indicates an area of necrosis.

form of post-translationally modified NF- $\mathrm{BB}$ p65) was also determined by western blotting. SIRT-1 expression levels were increased in the HMP group compared with the CS group ( $1.16 \pm 0.16$ vs. $0.53 \pm 0.12 ; \mathrm{P}=0.035$; Fig. 7$)$. In addition, the protein expression of acetylated-NF- $\kappa \mathrm{B}$ p65 was significantly reduced by HMP preservation when compared with CS preservation $(0.24 \pm 0.04$ vs. $1.06 \pm 0.23$; $\mathrm{P}=0.023$; Fig. 7$)$. IL- 6 and TNF- $\alpha$ are NF- $\mathrm{BB}-$ mediated genes. Therefore, to assess the level of the NF-kB p65-induced inflammatory response, the mRNA expression of the inflammatory cytokines IL- 6 and TNF- $\alpha$ was determined. The mRNA expression of IL- 6 was significantly reduced in the HMP group compared with the CS group $\left(0.26 \pm 0.03\right.$ vs. $1.01 \pm 0.08 ; \mathrm{P}=3.06 \times 10^{-8} ;$ Fig. $\left.8 \mathrm{~A}\right)$. Similar results were obtained for TNF- $\alpha$ expression in the HMP and the CS groups $\left(0.54 \pm 0.04\right.$ vs. $1.03 \pm 0.06 ; \mathrm{P}=2.59 \times 10^{-6} ;$ Fig. $\left.8 \mathrm{~B}\right)$. These results indicated that the inflammatory response induced by NF- $\mathrm{B}$ p 65 was attenuated by HMP preservation.

In addition to the protein expression of SIRT-1 and acetylated-NF-кB p65, SIRT-1 activity indicators (hepatic $\mathrm{NAD}^{+}$levels and $\mathrm{NAD}^{+} / \mathrm{NADH}$ ratio) were also measured. Consistent with results for SIRT-1 protein expression (Fig. 7), SIRT-1 activity was increased in the DCD livers preserved by HMP compared with the CS group, as indicated by higher levels of $\mathrm{NAD}^{+}(188.14 \pm 16.89$ vs. $90.61 \pm 12.03 \mathrm{nmol}$ $\mathrm{NAD}^{+} / \mathrm{g}$ protein; $\mathrm{P}=0.009$; Fig. $\left.9 \mathrm{~A}\right)$ and $\mathrm{NAD}^{+} / \mathrm{NADH}$ ratio $(2.13 \pm 0.43$ vs. $0.42 \pm 0.11 ; \mathrm{P}=0.018$; Fig. $9 \mathrm{~B})$. These results
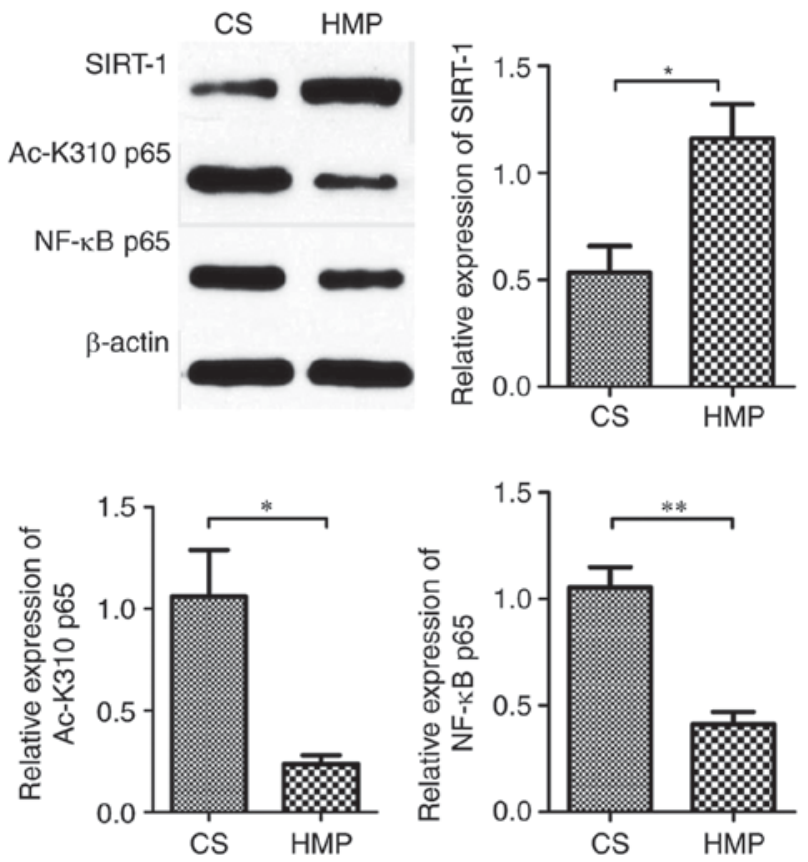

Figure 7. Effect of HMP on the protein expression of SIRT-1, Ac-K310 p65 and $\mathrm{NF}-\kappa \mathrm{B}$ p 65 at the end of reperfusion. Data are presented as the mean \pm standard error of the mean. ${ }^{*} \mathrm{P}<0.05$ and ${ }^{* *} \mathrm{P}<0.01$, as indicated. HMP, hypothermic machine perfusion; SIRT-1, sirtuin-1; Ac-, acetylated-; NF- $\kappa \mathrm{B}$ nuclear factor- $\kappa \mathrm{B} ; \mathrm{CS}$, cold storage.

indicate that HMP preservation may attenuate the hepatic $\mathrm{NF}-\kappa \mathrm{B}$ p65-induced inflammatory response in DCD rats via SIRT-1-mediated deacetylation of NF-кB p65.

\section{Discussion}

The increasing demand for liver transplantation from DCD donors means that enhanced organ preservation strategies against IRI are required. IRI involves multiple complex mechanisms, including direct ischemic damage to hepatocytes, indirect cellular injury resulting from the accumulation of reactive oxygen species (ROS) and inflammatory response (28-30). The results of the present study indicate that HMP exhibits a higher efficiency in preserving the functional and structural liver integrity by attenuating IRI.

Cellular depletion of ATP due to $\mathrm{O}_{2}$ shortage is a major cause of IRI, which in turn induces serious deleterious effects on hepatocytes (31). Hypothermia slows the cellular metabolism and reduces $\mathrm{O}_{2}$ demands, however, the mitochondrial functions are not terminated. It was previously reported that HMP preservation solution had sufficient dissolved $\mathrm{O}_{2}$ for cellular aerobic respiration, even in the absence of active oxygenation (4). In the current study, the compromised $\mathrm{O}_{2}$ consumption during reperfusion in the CS group was significantly improved by HMP, leading to higher ATP levels. This result is consistent with previous reports indicating that HMP provided sufficient $\mathrm{O}_{2}$ supply to meet the demands of cellular metabolism by a continuous circulation of hypothermic solution $(4,32,33)$. Furthermore, bile production during reperfusion was determined to assess the functional recovery of the livers. In the present study, although not statistically significant, bile production in the HMB group was marginally higher 

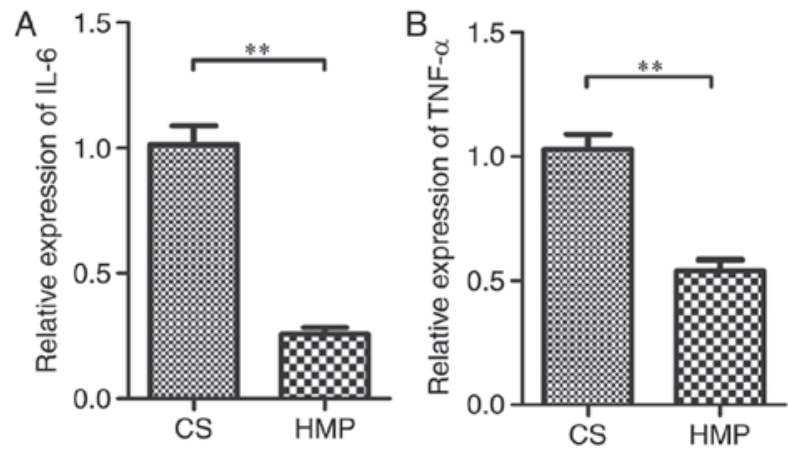

Figure 8. mRNA expression of inflammatory cytokines at the end of reperfusion in CS and HMP groups. (A) IL-6 and (B) TNF- $\alpha$ mRNA expression in CS and HMP groups following reperfusion. Data are presented as the mean \pm standard error of the mean. ${ }^{* *} \mathrm{P}<0.01$, as indicated. CS, cold storage HMP, hypothermic machine perfusion; IL, interleukin; TNF, tumor necrosis factor.
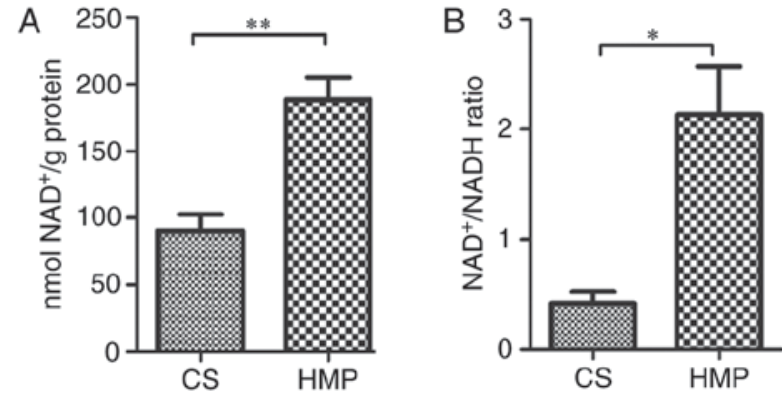

Figure 9. Levels of $\mathrm{NAD}^{+}$and the ratio of $\mathrm{NAD}^{+} / \mathrm{NADH}$ following reperfusion in $\mathrm{CS}$ and HMP groups. (A) $\mathrm{NAD}^{+}$levels and (B) $\mathrm{NAD}^{+} / \mathrm{NADH}$ ratio at the end of reperfusion in CS and HMP groups. Data are presented as the mean \pm standard error of the mean. ${ }^{*} \mathrm{P}<0.05$ and ${ }^{* *} \mathrm{P}<0.01$, as indicated. NAD, nicotinamide adenine dinucleotide; CS, cold storage; HMP, hypothermic machine perfusion.

compared with the CS group. This may be attributed to the fact that the blood supply of bile duct came from the hepatic artery, which was not perfused. The current study performed perfusion via the portal vein, which may have led to insufficient $\mathrm{O}_{2}$ and nutrient supply for the bile duct.

Oxidative damage incurred by ROS generated under hypothermia and hypoxia conditions is a crucial factor for determining the severity of IRI. The present study observed a significant reduction in the levels of the oxidative stress marker, MDA, indicating that oxidative damage to the graft was attenuated following HMP preservation compared with CS preservation. Furthermore, an increase in the activity of SOD following reperfusion was observed in HMP preservation compared with CS, which indicates a cellular attempt to ameliorate the oxidative damage.

The inflammatory response has a pivotal role in liver IRI. In the present study, RT-qPCR demonstrated that the mRNA expression of the inflammatory cytokines IL-6 and TNF $\alpha$ were significantly decreased in HMP compared with the CS group. Furthermore, the parenchymal integrity was examined by detecting the release of ALT, AST and LDH enzymes. The results demonstrated a significant reduction in the ALT, AST and LDH levels in samples preserved by HMP compared with CS at the different time points. Similar results were also observed in histological analysis. HMP preservation improved the histological structure of DCD livers compared with CS. These results verify that HMP improved the preservation of the cellular integrity of hepatocytes compared with the CS technique. The lower level of enzyme release and improved histological results may be attributed to the improvement of $\mathrm{O}_{2}$ consumption and ATP levels, and the attenuation of oxidative damage and inflammatory response following HMP preservation. These results were consistent with previous reports (4-6).

$\mathrm{NF}-\kappa \mathrm{B}$ p65 has been reported to have a critical role in the development of oxidative damage and inflammatory response in IRI (12-15). Compared with the CS group, the protein expression of $\mathrm{NF}-\kappa \mathrm{B}$ p65 was significantly reduced by HMP preservation. Furthermore, the mRNA expression on the inflammatory cytokines IL- 6 and TNF- $\alpha$, members of the $\mathrm{NF}-\kappa \mathrm{B}$ p65 transcript genes (34), were significantly decreased in the HMP livers. Therefore, we hypothesized that HMP may inhibit the inflammatory response during IRI by reducing the activation of NF- $\kappa$ B p65. However, the upstream molecular mechanism required further investigation.

In the mitochondria, hypoxia causes the dysfunction of respiratory chain, which subsequently leads to a decrease in the levels of $\mathrm{NAD}^{+}$and ratio of $\mathrm{NAD}^{+} / \mathrm{NADH}$ (31). As a dynamic preservation technique, it has been reported that HMP provides sufficient $\mathrm{O}_{2}$ supply by the continuous circulation of the hypothermic solution to maintain the cellular metabolism (4). Consistent with this report, the results of the present study demonstrated that HMP livers exhibited significantly increased $\mathrm{O}_{2}$ consumption, leading to higher $\mathrm{NAD}^{+}$levels and ratio of $\mathrm{NAD}^{+} / \mathrm{NADH}$ compared with livers preserved by $\mathrm{CS}$. SIRT-1, a class III histone deacetylase, has been reported to reduce IRI through various cellular processes. SIRT-1 activity requires the presence of $\mathrm{NAD}^{+}$as a substrate to deacetylate the downstream proteins $(16-18,35,36)$. In addition, SIRT-1 was previously reported to protect the liver from IRI (16-18). In the present study, DCD livers preserved by HMP exhibited a significantly higher expression of SIRT-1 compared with the CS group, indicating the superiority of HMP preservation in protecting DCD rat livers from IRI. This result, combined with the increase in $\mathrm{NAD}^{+}$levels and the ratio of $\mathrm{NAD}^{+} / \mathrm{NADH}$, and the reduced expression of NF- $\kappa \mathrm{B}$ p65, IL-6 and TNF- $\alpha$, led us to hypothesize that HMP preservation may ameliorate the $\mathrm{NF}-\kappa \mathrm{B}$ p 65 -induced inflammatory response during IRI in DCD rat livers via a SIRT-1-NAD ${ }^{+}$dependent pathway.

Yeung et al (19) previously reported that SIRT-1 inhibited the transcriptional activity of NF- $\mathrm{BB}$ p 65 by deacetylating RelA/p65, a subunit of NF- $\kappa \mathrm{B}$, at lysine 310 in non-small-cell lung cancer cells. In the present study, the acetylation at lysine 310 (K310) of NF- $\mathrm{B}$ p 65 in the HMP group was significantly decreased compared with the CS group, which indicates that HMP may attenuate the inflammatory response during IRI via SIRT-1 mediated deacetylation of NF- $\mathrm{B}$ p65.

In conclusion, compared with $\mathrm{CS}$, HMP preservation provided a more sufficient $\mathrm{O}_{2}$ supply to maintain the cellular metabolism, leading to increased levels of $\mathrm{NAD}^{+}$and the ratio of $\mathrm{NAD}^{+} / \mathrm{NADH}$, which subsequently enhanced SIRT-1 activity. The activation of SIRT-1 by HMP led to the inhibition of $N F-\kappa B$ p65 activity via the deacetylation of $N F-\kappa B$ p65 at K310 to attenuate the inflammatory response during IRI. Therefore, the present study demonstrates that HMP may 
reduce IRI by activation of a novel deacetylating pathway in DCD rat livers. These findings may provide a theoretical basis for the clinical application of HMP as an effective strategy to preserve DCD livers.

\section{Acknowledgements}

The present study was supported by the National Natural Science Foundation of China (grant no. U1403222).

\section{References}

1. Blok JJ, Detry O, Putter H, Rogiers X, Porte RJ, van Hoek B, Pirenne J, Metselaar HJ, Lerut JP, Ysebaert DK, et al: Longterm results of liver transplantation from donation after circulatory death. Liver Transpl 22: 1107-1114, 2016.

2. Perico N, Cattaneo D, Sayegh MH and Remuzzi G. Delayed graft function in kidney transplantation. Lancet 364: 1814-1827, 2004.

3. Brasile L, Stubenitsky BM, Booster MH, Arenada D, Haisch C and Kootstra G. Hypothermia a limiting factor in using warm ischemically damaged kidneys. Am J Transplant 1: 316-320, 2001.

4. Henry SD, Nachber E, Tulipan J, Stone J, Bae C, Reznik L, Kato T, Samstein B, Emond JC and Guarrera JV: Hypothermic machine preservation reduces molecular markers of ischemia/reperfusion injury in human liver transplantation. Am J Transplant 12 2477-2486, 2012.

5. Carnevale ME, Balaban CL, Guibert EE, Bottai $H$ and Rodriguez JV: Hypothermic machine perfusion versus cold storage in the rescuing of livers from non-heart-beating donor rats. Artif Organs 37: 985-991, 2013.

6. Guarrera JV, Henry SD, Samstein B, Odeh-Ramadan R, Kinkhabwala M, Goldstein MJ, Ratner LE, Renz JF, Lee HT, Brown RS Jr and Emond JC: Hypothermic machine preservation in human liver transplantation: The first clinical series. Am J Transplant 10: 372-381, 2010.

7. Taylor MJ and Baicu SC: Current state of hypothermic machine perfusion preservation of organs: The clinical perspective. Cryobiology 60 (3 Suppl): S20-S35, 2010.

8. Arnaudo AM and Garcia BA: Proteomic characterization of novel histone post-translational modifications. Epigenetics Chromatin 6: 24, 2013.

9. Chen LF and Greene WC: Assessing acetylation of NF-kappaB. Methods 36: 368-375, 2005.

10. Huang B, Yang XD, Lamb A and Chen LF: Posttranslational modifications of NFkappaB: Another layer of regulation for NF-kappaB signaling pathway. Cell Signal 22: 1282-1290, 2010.

11. Chen LF, Mu Y and Greene WC: Acetylation of RelA at discrete sites regulates distinct nuclear functions of NF-kappaB. EMBO J 21: 6539-6548, 2002.

12. Sun T, Luo J, Jia M, Li H, Li K and Fu Z: Small interfering RNA-mediated knockdown of NF- $\kappa$ Bp 65 attenuates neuropathic pain following peripheral nerve injury in rats. Eur J Pharmacol 682: 79-85, 2012.

13. Ramachandran S, Liaw JM, Jia J, Glasgow SC, Liu W, Csontos K, Upadhya GA, Mohanakumar T and Chapman WC: Ischemia-reperfusion injury in rat steatotic liver is dependent on NFאB P65 activation. Transpl Immunol 26: 201-206, 2012.

14. Andrade-Silva AR, Ramalho FS, Ramalho LN, Saavedra-Lopes M, Jordão AA Jr, Vanucchi H, Piccinato CE and Zucoloto S: Effect of NFkappaB inhibition by CAPE on skeletal muscle ischemia-reperfusion injury. J Surg Res 153: 254-262, 2009.

15. Suetsugu H, Iimuro Y, Uehara T, Nishio T, Harada N, Yoshida M, Hatano E, Son G, Fujimoto J and Yamaoka Y: Nuclear factor $\{$ kappa\}B inactivation in the rat liver ameliorates short term total warm ischaemia/reperfusion injury. Gut 54: 835-842, 2005.

16. Zhang C, Li X and Liu Q: Sorbitol dehydrogenase inhibitor protects the liver from ischemia/reperfusion-induced injury via elevated glycolytic flux and enhanced sirtuin 1 activity. Mol Med Rep 11: 283-288, 2015.

17. Yan H, Jihong Y, Feng Z, Xiaomei X, Xiaohan Z, Guangzhi W, Zhenhai M, Dongyan G, Xiaochi M, Qing F, et al: Sirtuin 1-mediated inhibition of p66shc expression alleviates liver ischemia/reperfusion injury. Crit Care Med 42: e373-e381, 2014.
18. Pantazi E, Zaouali MA, Bejaoui M, Serafin A, Folch-Puy E, Petegnief V, De Vera N, Ben Abdennebi H, Rimola A and Roselló-Catafau J: Silent information regulator 1 protects the liver against ischemia-reperfusion injury: Implications in steatotic liver ischemic preconditioning. Transpl Int 27: 493-503, 2014.

19. Yeung F, Hoberg JE, Ramsey CS, Keller MD, Jones DR, Frye RA and Mayo MW: Modulation of NF-kappaB-dependent transcription and cell survival by the SIRT1 deacetylase. EMBO J 23: 2369-2380, 2004.

20. Institute of laboratory animal resources (US). Committee on care, use of laboratory animals and national institutes of health (US). Division of research resources: Guide for the care and use of laboratory animals. 8th edition. National academies press, Washington, DC, 2011.

21. Pizarro MD, Rodriguez JV, Mamprin ME, Fuller BJ, Mann BE, Motterlini R and Guibert EE: Protective effects of a carbon monoxide-releasing molecule (CORM-3) during hepatic cold preservation. Cryobiology 58: 248-255, 2009.

22. Balaban CL, Rodriguez JV and Guibert EE: Delivery of the bioactive gas hydrogen sulfide during cold preservation of rat liver: Effects on hepatic function in an ex vivo model. Artif Organs 35: 508-515, 2011.

23. Schlegel A, Kron P, Graf R, Dutkowski P and Clavien PA: Warm vs. cold perfusion techniques to rescue rodent liver grafts. J Hepatol 61: 1267-1275, 2014.

24. Kamada N and Calne RY: A surgical experience with five hundred thirty liver transplants in the rat. Surgery 93: 64-69, 1983.

25. Minor T, Manekeller S, Sioutis M and Dombrowski F: Endoplasmic and vascular surface activation during organ preservation: Refining upon the benefits of machine perfusion. Am J Transplant 6: 1355-1366, 2006.

26. Minor T and Manekeller S: Assessment of hepatic integrity after ischemic preservation by isolated perfusion in vitro: The role of albumin. Cryobiology 54: 188-195, 2007.

27. Livak KJ and Schmittgen TD: Analysis of relative gene expression data using real-time quantitative PCR and the 2(-Delta Delta C(T)) method. Methods 25: 402-408, 2001

28. Khandoga A, Biberthaler P, Enders G and Krombach F: 5-Aminoisoquinolinone, a novel inhibitor of poly(adenosine disphosphate-ribose) polymerase, reduces microvascular liver injury but not mortality rate after hepatic ischemia-reperfusion. Crit Care Med 32: 472-477, 2004.

29. Lentsch AB, Kato A, Yoshidome H, McMasters KM and Edwards MJ: Inflammatory mechanisms and therapeutic strategies for warm hepatic ischemia/reperfusion injury. Hepatology 32: 169-173, 2000.

30. Yamamoto T, Ono T, Ito T, Yamanoi A, Maruyama I and Tanaka T: Hemoperfusion with a high-mobility group box 1 adsorption column can prevent the occurrence of hepatic ischemia-reperfusion injury in rats. Crit Care Med 38: 879-885, 2010.

31. Peralta C, Jiménez-Castro MB and Gracia-Sancho J: Hepatic ischemia and reperfusion injury: Effects on the liver sinusoidal milieu. J Hepatol 59: 1094-1106, 2013.

32. Jia JJ, Zhang J, Li JH, Chen XD, Jiang L, Zhou YF, He N, Xie HY, Zhou L and Zheng SS: Influence of perfusate on liver viability during hypothermic machine perfusion. World J Gastroenterol 21: 8848-8857, 2015.

33. Vekemans K, Liu Q, Brassil J, Komuta M, Pirenne J and Monbaliu D: Influence of flow and addition of oxygen during porcine liver hypothermic machine perfusion. Transplant Proc 39: 2647-2651, 2007.

34. Pamukcu B, Lip GY and Shantsila E: The nuclear factor-kappa B pathway in atherosclerosis: A potential therapeutic target for atherothrombotic vascular disease. Thromb Res 128: 117-123, 2011.

35. Lin SJ, Ford E, Haigis M, Liszt G and Guarente L: Calorie restriction extends yeast life span by lowering the level of NADH. Genes Dev 18: 12-16, 2004.

36. Vaziri H, Dessain SK, Ng Eaton E, Imai SI, Frye RA, Pandita TK, Guarente L and Weinberg RA: hSIR2(SIRT1) functions as an NAD-dependent p53 deacetylase. Cell 107: 149-159, 2001. 